\title{
Estudiantes universitarios frente a las infecciones de transmisión sexual. Un estudio de audiencia desde la comunicación para la salud
}

Recibido: 13 de febrero de 2013

Aceptado: 27 de agosto de 2013

Publicado: 29 de noviembre de 2013
Acianela Montes de Oca

amontes@ucab.edu.ve

Universidad Católica Andrés Bello (Venezuela)

Resumen: Las estadísticas de los principales organismos internacionales de salud demuestran que los mayores afectados por las infecciones de transmisión sexual (ITS) son los jóvenes, en los que además pueden tener consecuencias que afecten el resto de sus vidas. Una investigación de audiencias para entender la forma en que una muestra seleccionada de estudiantes universitarios construye ideas sobre estas enfermedades, cómo se reflejan estas nociones en su práctica sexual y por cuáles medios prefieren enterarse sobre el tema revela que los medios tradicionales ya no están dentro de los principales espacios en los que se informan o comparten ideas sobre ITS. Tampoco sus centros de estudio les aportan información confiable sobre el tema. Prefieren la relación cara a cara, internet y las redes sociales en la medida en que permiten interactividad y diálogo. Se inclinan por una perspectiva lúdica, así como información práctica y útil antes que por largas recomendaciones.

Palabras clave: Comunicación para la salud, infecciones de transmisión sexual, estudiantes universitarios, jóvenes.

Abstract: The statistics of the major international health organizations, shows that most affected by sexually transmitted infections (STIs) are young, which also can have consequences that affect the rest of their lives. An audience study to understand how a selected sample of university students construct ideas about these diseases, how these notions are reflected in their sexual practice, and what sources prefer to learn on the subject, reveals that traditional media are no longer within of the main areas in which they obtain information or share ideas about STIs. Neither their schools provide reliable information on the subject. They prefer face-to-face communication, and the Internet and social networks to the extent that allow interactivity and dialogue. They favor a playful perspective as well as practical and useful information. 
Key words: Health Communication, Sexually Transmitted Infections, College Students, Youngs.

\section{Introducción}

Los reportes de los organismos mundiales de salud hacen pensar que uno de los aspectos más hermosos y determinantes de nuestra condición de especie triunfante en el planeta, la sexualidad, está sacudido por las infecciones de transmisión sexual (ITS). VIH-sida, virus de papiloma humano (VPH) y herpes sexual, clamidiasis, se han unido a las ya conocidas y temibles sífilis e infecciones gonocóccicas, con altos saldos de muerte e incapacidad en todo el mundo y en todos los sectores de la población. Lo doloroso es que en un enorme porcentaje de los casos es posible evitar estas enfermedades con una decisión individual, con la simple intención de protegerse a través de un método de barrera como el preservativo y, sobre todo, con la determinación de vivir la sexualidad de manera responsable, para que siempre sea placentera.

Dado que, según las estadísticas, el principal afectado por este avance de las ITS es el público juvenil, se decidió hacer una investigación de audiencias para aproximarnos a la forma en que una muestra seleccionada de estudiantes universitarios construyen ideas sobre estas enfermedades, cómo se reflejan estas nociones en su práctica sexual y por cuáles medios prefieren enterarse sobre el tema.

\section{Algunas precisiones sobre las infecciones de transmisión sexual}

Las enfermedades de transmisión sexual históricamente han sido un grave problema de salud pública en todo el planeta. Bastaría recordar los relatos de pesadilla provocados por la gonorrea y especialmente la sífilis desde el siglo XV, así como los estragos que hizo entre la población indígena de América. La difusión de esta temible enfermedad, que no sólo no ha sido erradicada, sino que sigue campeando en Europa y en los Estados Unidos, tal vez se habría mantenido encubierta por el desprecio y el "pudor" de la época, si no hubiera causado víctimas entre famosos artistas e intelectuales del siglo XIX, como Henri de Toulouse-Lautrec, Vincent Van Gogh y Friedrich Nietzsche, según han sugerido algunos autores (Barrios, 1999).

Y justamente cuando se pensaba que el avance médico-científico sería capaz de controlar, si no eliminar por completo estas infecciones, a finales del siglo pasado fuimos testigos de un recrudecimiento de las enfermedades de transmisión sexual. La sífilis y la gonorrea, de rancia estirpe, reaparecieron con nuevos bríos, y otros nombres hicieron su ingreso en el imaginario colectivo: hepatitis B, clamidia, herpes, virus de papiloma humano $\mathrm{y}$, sobre todo, el VIH-sida. El panorama se ensombreció al punto de que una parte importante de la población mundial tiene comprometida su vida y su futuro por algunas de estas infecciones de transmisión sexual (ITS). Según datos de ONUSIDA, en su informe para diciembre de 2012, más de 34 millones de personas viven con el VIH, de los cuales la mitad conoce su estado serológico. Cada año se infectan con el virus 2,5 millones de personas y 1,7 millones de personas han fallecido a causa del sida y sus complicaciones. Esa organización ha 
establecido que los jóvenes constituyen el $40 \%$ del total de los nuevos adultos infectados por el VIH: 5 millones de jóvenes viven con la enfermedad y cada día más de 2.400 jóvenes contraen la infección. Los jóvenes continúan en el centro de la epidemia, pero también podrían cambiar su curso de forma definitiva.

En Venezuela, como en otros países, la población más afectada por sida está en plena edad productiva. De acuerdo con ONUSIDA Venezuela (2012), el número de seropositivos se estima en 99 mil (pero podría estar entre 54 mil y 230 mil personas). La edad promedio de la mayoría de los afectados en el país oscila entre los 15 y los 49 años, y se estima que el número de fallecimientos por sida fue de 2.900 personas (aunque podría estar entre mil y 9.600). Las cifras oficiales del Ministerio del Poder Popular para la Salud (MPPS, 2011) sitúan la prevalencia en la población de entre 15 y 24 años en 0,4 . La forma de transmisión predominante es la sexual y es responsable del 58,8 por ciento de los casos. No hay información sobre pruebas de detección del VIH ni uso de preservativos en este grupo etario.

El sida es, probablemente, el peor problema, pero no el único. Las estadísticas del MPPS (2011) indican que la sífilis supera en número de casos al VIH-sida y lo mantienen en el 2do lugar, mientras que las infecciones gonocóccicas se afianzan en el tercer lugar de morbilidad por infecciones de transmisión sexual. Incluso, la sífilis congénita se encuentra en crecimiento. Datos de la Red de Sociedades Científicas Médicas Venezolanas (2013) establecen que en 2011 hubo 38,4\% más casos de sífilis congénita que en 2010, lo cual sería, entre otras cosas, indicador de ineficiente control prenatal.

El cáncer de cuello uterino, por su parte, es el responsable de la muerte de mil venezolanas cada año y es la primera causa de muerte por cáncer en mujeres en nuestro país. Cada año se registran 2.500 nuevos casos de esta enfermedad que va en ascenso desde 1985 . El grupo de riesgo para padecerla abarca unos 3 millones de mujeres, y según las cifras del MPPS (2011), un 2\% de ellas ya está desarrollando una lesión maligna o premaligna. Venezuela está entre los países latinoamericanos con más alta incidencia. Entre los factores que determinan la aparición del cáncer de cuello uterino, destacan el inicio precoz de las relaciones sexuales, la promiscuidad sexual (se considera promiscuo a quien tenga más de tres parejas sexuales distintas al año) y la infección con ciertos virus de papiloma humano (VPH). El virus del papiloma humano, si bien en el país no es enfermedad de notificación obligatoria, se considera la cuarta infección de transmisión sexual frecuente en la población.

En Venezuela, el MPPS no ofrece estadísticas sobre los casos de infección por VPH ni ha aprobado las vacunas que existen contra esa infección, de modo que sólo se tienen informaciones aisladas e inconexas sobre la incidencia de la enfermedad. Un indicador relevante para este trabajo es la investigación de Correnti y otros (2002) que tomó como muestra estudiantes cuya edad promedio era de 25 años (rango de 16-35 años), atendidos en el servicio de Obstetricia y Ginecología de la Organización de Bienestar Estudiantil de la Universidad Central de Venezuela. En la población evaluada, se detectó el genoma viral de VPH en un rango entre $60-75 \%$ a $85 \%$, dependiendo de la zona geográfica y de los grupos poblacionales estudiados. Por otra parte, hallaron que $80 \%$ de la población femenina infectada tenía VPH oncogénico de alto riesgo. 


\title{
3. Los jóvenes: Una población especialmente afectada
}

Una pregunta que parece obvia es: ¿Por qué, si las ITS están tan difundidas, circula tan poca información sobre ellas? Una simple revisión de los periódicos y la televisión un día cualquiera de nuestras vidas, permite fijarse en que salvo el VIH-sida (y más en un enfoque del problema que con criterios de divulgación o educación para la salud), el resto de las ITS parecen ausentes en la agenda de los medios de comunicación. Aparentemente, la carga de rechazo social que gravita sobre estas enfermedades es tan grande que ni siquiera el riesgo de muerte que corren quienes pudieran infectarse con algunas de ellas es suficiente para descorrer el telón que las oculta.

El doctor Leoncio Barrios, investigador de la Universidad Central de Venezuela y ex director del Programa Nacional de VIH-sida del MPPS, insiste en que por estar asociadas a lo sexual, las ITS están encerradas en un juicio moral (el sentido de pecado, por una parte, y la vinculación con conductas impropias, por la otra). Lo sexual, en nuestra cultura cristiana, se ha asociado a lo censurable y por tanto es algo de lo que no se habla sino en voz baja:

\begin{abstract}
"Pero además de ello, las ITS se asocian a promiscuidad -entiéndase este término como conductas sexualmente indiscriminadas, con múltiples parejas-, al incumplimiento del sagrado deber del celibato o al haber violado los votos de fidelidad conyugal, a la asistencia a burdeles, al sexo comercial, ilegal. Es decir, a lo indebido. Las ITS también se han asociado a un problema de higiene: se supone que se infectan sexualmente quienes carecen de adecuados hábitos higiénicos: los sucios y sucias. Aquellos que practican la suciedad física y moral” (Barrios, 1999: 7).
\end{abstract}

Aparentemente, padecer una ITS es convertirse en merecedor de una sanción social. Y de esas cosas no se habla con los hijos o con los jóvenes: hay que librarlos de la vergüenza. De allí que ni siquiera en el consultorio de los ginecólogos o en las salas de planificación familiar sea fácil hablar sobre estas enfermedades. El resultado de este velo social lo encontramos en las dolorosas cifras de transmisión entre nuestros jóvenes, principales víctimas de ese silencio. Recordemos que es entre los menores de 25 años donde se produce la mayor parte de las infecciones de carácter sexual, no sólo porque ellos tienen una mayor actividad sexual (por razones biológicas y hormonales, por una parte), con el riesgo que ello implica, sino también por ciertas características psicológicas de esa fase del desarrollo humano ${ }^{1}$, que según la doctora Irene Sáez, especialista en medicina del adolescente, pueden resumirse así:

"Se siente omnipotente e invulnerable; duda, analiza y cuestiona todos los conceptos religiosos y la organización político-social en que vive; reclama de los adultos una conducta coherente con lo que expresan, así que cuestiona

\footnotetext{
1 Autores como Sáez y Sileo (1992) han establecido tres etapas dentro de la adolescencia: temprana, media y tardía. La adolescencia tardía (entre los 17 y 21 años) se corresponde con las edades de los jóvenes universitarios, objeto de nuestro estudio.
} 
a todo y todos. Varía constantemente su estado anímico. Pasa por fases de depresión serias, que en algunos casos pueden tener consecuencias importantes ( $20 \%$ del total de suicidios registrados ocurren en adolescentes); define gradualmente su identidad sexual, en un proceso que comienza en el autoerotismo (masturbación) y experiencias ocasionales con adolescentes de su mismo sexo, hasta llegar a la definición sexual; tiende a estar en grupos con otros adolescentes. Se viste, habla y conduce según las normas del grupo, para así reforzar su yo; necesita intelectualizar y fantasear: piensa y analiza la información que recibe para sacar sus propias conclusiones; se inicia en la toma de conciencia social; se está orientado temporalmente: todo es 'ahora o nunca', o 'hay tiempo para todo"” (Sáez y Sileo, 1992).

Uno de los principales retos y limitaciones para cambiar la conducta de los jóvenes ante las ITS es su convicción de que ese problema no les afecta. Se sienten invulnerables y, por tanto, sienten que el riesgo de infectarse no les compete. También es determinante la construcción de su autoimagen corporal. La etapa de narcisismo, característica de la adolescencia, los hace muy susceptibles a defender su aspecto e imagen, de modo que fantasean sobre sus cuerpos y la forma en que quieren mostrarse y comportarse. En general, quieren "verse bien".

En el caso venezolano, coexisten otros factores sociales que contribuyen a aumentar el riesgo de nuestros jóvenes. Entre ellos están la temprana iniciación sexual y el embarazo precoz. Las cifras oficiales disponibles para perfilar la iniciación sexual de los venezolanos provienen de la Encuesta nacional de población y familia de 1998 (ápud Freitez, 2001). El 50\% de las adolescentes se inicia sexualmente antes de los 19 años y el 10\% antes de los 15 . En zonas menos urbanizadas y rurales la edad disminuye: el 30\% se inicia antes de los 15 años y el $70 \%$ antes de los 19. Otra cifra importante proviene de la Comisión de Epidemiología de la Red de Sociedades Científicas y Médicas de Venezuela (RSCMV), en su boletín de febrero de 2012. Según la mencionada publicación, de los 591.303 partos registrados en 2010, 130.888 fueron de menores de 19 años y 7.778 de adolescentes que no superaban los 15 años. La tasa de embarazo en adolescentes en Venezuela es superior al $26 \%$ y se considera una de las más altas en América Latina. De hecho, 21\% de los nacimientos vivos en todo el país provienen de jóvenes de entre 15 y 19 años, es decir, una de cada cinco menores de edad ya es madre. Estas cifras se mantienen sin diferencia en los estratos sociales (RSCMV, 2012).

Otras investigaciones sobre infecciones de transmisión sexual en estudiantes también aportan datos importantes. Agüiño (2010) en su estudio sobre el virus de papiloma humano en estudiantes de la Universidad Católica Andrés Bello, en Caracas (Venezuela) detectó que el $71 \%$ de los jóvenes objeto de estudio (entre 17 y 23 años) ya habían tenido relaciones sexuales, todos habían escuchado hablar de las ITS, especialmente en los centros educativos de educación media, pero no estaban particularmente interesados en la información porque la consideraban ajena. Esta actitud solo cambiaba en los casos en los que habían tenido alguna experiencia cercana con las ITS (ya fuera porque estuvieran infectados o porque alguien cercano padeciera la enfermedad). Las muchachas eran las más sensibilizadas sobre el tema. 
Otro aspecto a revisar es la exposición a medios de comunicación, que se constituyen en referentes si no hay una mediación efectiva del grupo parental. A pesar de las múltiples discusiones sobre el efecto de los medios en las audiencias, existen evidencias de que la información recibida de la televisión se puede convertir en un modelo a imitar en grupos vulnerables (Santoro, 1998). De allí la importancia que se concede a los contenidos emitidos por este medio. En Venezuela, el tiempo dedicado a ver televisión es equivalente al dedicado a la escuela: entre 4 y 5 horas diarias, es decir, el $45 \%$ del tiempo libre.

\section{Los medios de comunicación: ¿Nuevos maestros?}

Justamente por su tiempo de exposición a los medios de comunicación, es importante comprender cómo es la relación de los jóvenes con los medios. En Venezuela, Marcelino Bisbal (ápud Guzmán y otros, 1998), detectó en su investigación sobre consumo cultural que un total de $43,8 \%$ de los encuestados afirman que después de un día de trabajo lo que prefiere hacer es ver televisión. Este porcentaje se eleva hasta el $60 \%$ mientras más bajo es el nivel sociocultural. Después, un $23.2 \%$ prefiere leer para distraerse, aunque no se nos indique qué tipo de lectura. Ese porcentaje desciende en la población de menor nivel socioeconómico, aunque se ubica en un $28.6 \%$ en los sectores de clase media alta. Para descansar el fin de semana, los venezolanos prefieren la televisión: 30\% con relación al $23,8 \%$ que prefiere pasear y muy por encima de otras prácticas como ir al cine, conversar, asistir a fiestas, ir a la playa, oír música, estudiar, etc. Leer es práctica común en 9,2\%, y leer el periódico, una decisión de apenas $0,7 \%$.

Parra (2004), en su investigación sobre las dinámicas de percepciones sobre prácticas de comunicación y salud en los jóvenes venezolanos, detectó que los jóvenes entre 16 y 19 años tienen como principal fuente de información sobre salud a los medios de comunicación, especialmente a la televisión, seguida por radio y prensa. En general, sienten que la agenda de los medios en materia de salud no los satisface:

"Piensan que los medios transmiten, principalmente, información sobre los daños que ocasionan las drogas en los consumidores, y eso les parece perfecto, pero creen que es importante que amplíen su espectro temático sobre otros temas de salud: cáncer, tabaquismo, niños de la calle, alcoholismo, hipertensión arterial, seguridad, embarazo temprano, sexualidad sana, entre otros" (Parra, 2004: 49).

La televisión, entonces, adquiere un papel protagónico como medio preferido por los jóvenes venezolanos en temas de salud. Esto es particularmente importante por cuanto hasta ahora, la información con que contamos sobre el impacto de este medio es contradictoria. Por ejemplo, se ha demostrado que en quienes la consumen en altas cantidades, como los jóvenes, la televisión parece conducirles a una visión alterada de la realidad. Cita Norberto González Gaitano una investigación realizada en Carolina del Norte sobre los efectos de los talk shows en una muestra de adolescentes de tres colleges de ese Estado norteamericano. 
"Quienes siguen este tipo de programas se imaginan una sociedad mucho más violenta de lo que realmente es. Así, por ejemplo, quienes ven a diario este tipo de programas creen que un $48 \%$ de sus coetáneos se escapan de casa, mientras que en la vida real lo hacen el $8 \%$. La cifra de adolescentes que quedan embarazadas antes de los 19 años es de un 4\%. Los teleadictos de estos programas creen que esto sucede en un 55\% de sus coetáneos. Lo mismo sucede respecto a otros indicadores de comportamiento inmoral, como la infidelidad conyugal, las relaciones sexuales prematrimoniales o el uso de armas en la escuela. Lo grave es que esta distorsión se da también entre los que no siguen los programas, en grado menor naturalmente. Lo cual hace pensar que la televisión incide sobre la percepción social en su conjunto, creando una especie de refracción perceptiva" (González, 2000: web).

González Gaitano, profesor de la Facoltà di Comunicazione Istituzionale de la Pontificia Università della Santa Croce, en Roma, también reflexiona sobre los efectos de la televisión sobre la sexualidad:

"El desnudo erótico de la publicidad y la exposición pública de la relación amorosa más íntima han desvirtuado el valor humano de esa realidad; son ya como la flor de plástico, el vino químico, y todos los demás 'pseudos' de nuestra sociedad artificial. Dice Thibon que 'la sexualidad humana normal gravita alrededor de dos polos: el apetito carnal y el amor espiritual. El erotismo actual es extraño tanto al uno como al otro'. Los consumidores de erotismo comercializado están doblemente frustrados: ni gozan de la dimensión espiritual del amor, porque 'la belleza es un fruto que se mira sin alargar la mano' (Simone Weil), ni se satisfacen siquiera en el ejercicio completo de la sexualidad, pues una nebulosa de imágenes inaccesibles se interponen entre su deseo y el objeto poseído" (ibídem).

Sin embargo, Leoncio Barrios, en su estudio sobre el uso de la televisión en la familia venezolana, precisa que los mensajes son mediados por la familia. Por tanto, la televisión será nociva o benéfica, dependiendo de cómo elabore los mensajes cada familia. El investigador cita a Goodman, quien dice que "la forma en que una familia usa la televisión es indicativa de cómo esa familia se comporta en general". Basado en sus investigaciones, el autor concluye que "cualquiera sea el contenido y la fuerza de la televisión, siempre queda la posibilidad de la acción mediadora de la familia para contrarrestar sus posibles efectos" (Barrios, 1993: 141).

Esta visión podría resultar más preocupante si recordamos que justamente, una de las instituciones venezolanas en mayor situación de crisis es la familia. Sin embargo, como también evidencian las investigaciones, ni la televisión ni el más poderoso de los medios de comunicación social es capaz de sustituir el impacto de la comunicación "cara a cara" para cambiar conductas y actitudes. Asimismo, es llamativo que los jóvenes suelan referirse a su preferencia por la conversación entre gente de su propia edad y charlas con voluntarios como los medios por los que obtienen mayor información sobre temas que les interesan, como por ejemplo la sexualidad y las ITS. 
Es la conclusión a la que llegaron las autoridades del Fondo de Población de las Naciones Unidas (FNUAP) en su informe sobre el Estado de la Población Mundial (1998), en el capítulo dedicado a los jóvenes. Según el informe, se sienten más cómodos hablando de esas cuestiones con otros jóvenes de la misma edad y a menudo expresan el deseo de aprender de otros jóvenes que conozcan el tema, como parte de los programas de educación sexual. Igualmente, un estudio realizado sobre estudiantes de cuatro escuelas técnicas de Khon Kaen, en Tailandia, reveló que los compañeros desempeñan un papel importante en ayudar a los adolescentes y los recursos de los servicios de salud. Sin embargo, un grupo importante de los jóvenes también dijo estar interesado en recibir información de parte de adultos (ya fuera padres, maestros o miembros del servicio de salud).

\section{La investigación}

Si asumimos que las ITS son un grave problema de salud pública, que aparentemente hace mayores estragos entre los jóvenes (lo cual compromete el futuro de nuestras sociedades), se justifica la importancia de una investigación que aspire a comprender cómo adquieren información sobre este tema los estudiantes universitarios y cómo preferirían obtenerla.

La presente investigación es un estudio exploratorio basado en los enfoques paradigmáticos de la investigación cualitativa (Rodríguez, Gil y García, 1996), que tiene como marco el método naturalista. Los objetivos específicos son determinar las vías por las que una muestra seleccionada de jóvenes universitarios obtiene información sobre las infecciones de transmisión sexual (ITS) más frecuentes en Venezuela; detectar cuáles medios prefieren los jóvenes seleccionados para obtener información sobre el tema; y establecer las formas en que los jóvenes seleccionados prefieren que se estructuren los mensajes sobre estas infecciones.

Como herramientas básicas, se eligieron la entrevista en profundidad y los grupos de discusión por su potencia para lograr información significativa, íntima, especialmente en temas rodeados de mitos y angustias, como el abordado en este trabajo. Como afirman Rodríguez, Gil y García, la entrevista en profundidad "es uno de los medios para acceder al conocimiento, las creencias, los rituales, la vida de esa sociedad o cultura, obteniendo datos en el propio lenguaje de los sujetos" (ibidem).

En cuanto a los "grupos de discusión", técnica usada frecuentemente en investigaciones cualitativas, se basa en la noción de que los grupos son capaces de reproducir, en su interacción, parte fundamental del sentido que se construye en la sociedad de la que son parte:

"El grupo de discusión es una técnica de investigación social que (como la entrevista abierta o en profundidad y las historias de vida) trabaja con el habla. En ella, lo que se dice -lo que alguien dice en determinadas condiciones de enunciación- se asume como punto crítico en el que lo social se reproduce y cambia, como el objeto, en suma, de las ciencias sociales. En toda habla se articula el orden social y la subjetividad [...] El grupo actúa así como una retícula que fija y ordena, según criterios de pertinencia, el sentido 
social correspondiente al campo semántico concreto en el que se inscribe la propuesta del prescriptor" (Canales y Peinado, 1999: 290).

En general, el grupo de discusión (sean cuales fueren las modalidades en las que se utilice) se caracteriza entre otras cosas por el hecho de que se constituye específicamente para la situación de trabajo que le plantea el prescriptor o coordinador. Además, se reúne para realizar una tarea y, por tanto, instaura un espacio de opinión colectiva. Según Canales y Peinado (1999), por genérico o simple que sea el problema analizado, el número de grupos de discusión que se desarrollen en una investigación debe ser de al menos dos, y cada grupo de discusión deberá situarse entre los cinco y diez participantes.

El estudio se realizó sobre estudiantes universitarios de las más importantes instituciones de educación superior del área Metropolitana de Caracas, con edades entre los 17 y los 24 años. Se seleccionaron buscando diversidad y la riqueza de información que pudieran aportar al trabajo. Las entrevistas en profundidad se realizaron a 15 estudiantes universitarios de la Universidades Simón Bolívar, Santa María, Central de Venezuela, Católica Andrés Bello y Metropolitana. Dos de ellos fueron seleccionados totalmente al azar, al inicio de investigación. En los restantes, fue necesario reorientar la búsqueda. Esto obedeció a que las muchachas parecían más proclives a brindar información y resultaba importante contar con varones que hablaran con claridad de estos temas por la posibilidad de detectar diferencias producto de una concepción de género. También fue importante entrevistar a estudiantes procedentes de sectores más empobrecidos, para saber si su opinión difería en algo de los otros jóvenes. Así que el último estudiante fue seleccionado atendiendo especialmente a su condición socieconómica.

Interesaba saber si estos estudiantes estaban informados acerca de las ITS, sobre cuáles de esas enfermedades tenían más conocimiento, y cómo habían adquirido esa información. Para que hablaran con libertad y se sintieran en confianza, fue necesario obviar el grabador y limitarse a tomar notas de las conversaciones. En la mayor parte de los casos, el lugar de la entrevista fue un escenario "neutral" (la casa de algún amigo o un café). Los jóvenes generalmente fueron desconfiados y recelosos, a pesar de las garantías acerca del uso de la información, de la confidencialidad reafirmada y de la obligatoria discreción de la autora de la investigación. Con más o menos detalles, compartieron esa información y hablaron sobre su forma de vida y de relacionarse entre sí. Los datos obtenidos de las entrevistas fueron sometidos a un análisis de tipo cualitativo, en el que se establecieron categorías a partir de ordenar la información que los jóvenes proporcionaron. Se optó por prescindir de las estadísticas, dado el paradigma desde el que se construyó la investigación.

En cuanto a los grupos de trabajo, se plantearon 2 grupos para establecer las preferencias de los estudiantes seleccionados por los medios y los contenidos por los que preferían obtener información sobre infecciones de transmisión sexual. Era relevante comprender si se exponían a los medios de comunicación, cuáles de esos medios les proveían de información sobre las ITS y sobre el mundo, y por cuál vía les interesaba obtener información sobre las ITS. El primer grupo estuvo constituido por seis estudiantes de las universidades Santa María (2), Católica Andrés Bello (2), Metropolitana (1) y Monteávila (1) que acudieron a 
la invitación pública que se hizo en esos centros de estudio. El segundo grupo se conformó por 7 jóvenes de las universidades Central de Venezuela (2), Simón Bolívar (2), Santa Rosa (1) y Católica Andrés Bello (2) que de alguna manera fueron informados y reclutados gracias a los anteriores participantes. Se logró que todos fueran de facultades, escuelas o departamentos diferentes.

Los criterios de selección fueron: edades (entre 17 y 23 años), sexo, estrato social y la condición de estudiantes universitarios. La duración de cada reunión fue de aproximadamente hora y media. Los grupos contaron con moderador, ayudante (un estudiante) y relator. Los grupos focales fueron grabados y luego transcritos para el análisis cualitativo de los contenidos. Para la discusión se realizó una guía temática para mantener la orientación de la discusión, que en algunos casos podía desordenarse o fragmentarse. La muestra seleccionada resultó homogénea en la medida en que los estudiantes pertenecen a la clase media o media baja, tienen entre 17 y 23 años y viven en Caracas. Esto probablemente hace que sus gustos e intereses, en muchos sentidos, sean comunes.

La perspectiva desde la que se realizó el trabajo se basa en la comunicación para la salud, definida por Gloria Coe, asesora de la Organización Panamericana de la Salud (OPS), como un proceso que permite construir comportamientos individuales y colectivos más sanos:

"[La comunicación para la salud es] la modificación del comportamiento humano y de los factores ambientales relacionados con ese comportamiento, los cuales directa o indirectamente promueven la salud, previenen enfermedades o protegen a los individuos del daño, o como el proceso de presentación y evaluación de la información educacional persuasiva, incorporativa y atractiva, que conduce a conductas individuales y sociales saludables" (Coe, 1998: 2).

La perspectiva de la comunicación para la salud privilegia el proceso comunicativo como un espacio de aprendizaje social, toma en consideración las intersubjetividades puestas en juego y propone una cultura de calidad de vida que sustituya a la cultura del miedo y de la enfermedad sobre la cual se han basado tradicionalmente los mensajes de comunicación para la salud.

\section{Discusión de resultados}

En las entrevistas no se notaron divergencias importantes entre lo que pensaban los muchachos y las muchachas, probablemente porque el énfasis de las preguntas no se orientaba hacia las diferencias de género. Otra explicación podría ser que esta diferenciación no sea un valor determinante entre los jóvenes de esta generación en materia de ITS y sexualidad.

Pareciera que la educación previa, seglar o religiosa, no es determinante en términos de la información que obtienen de las instituciones en las que estudian el bachillerato. Ninguno de ellos dijo haberse informado sobre ITS en el pensum formal. Pero todos afirman haber hablado del asunto durante la educación media. Esta etapa parece crítica entonces para efectos de comunicarse con los estudiantes. Lo que no se pudo detectar durante este estudio 
es si se enteran a principios de bachillerato (hacia los 12 ó 13 años) o al final (hacia los 15 años). Todos solicitan información clara durante estos años y en la casa, aunque la mayoría no parece proclive a conversar sobre estos temas con los padres (“¿Hablar de esto con mi mamá? ¡Me mata!”, dijo una de nuestras entrevistadas).

Todos se manifiestan activos sexualmente y se protegen del embarazo, no de las ITS. Se inician en la sexualidad hacia los 15 años (los varones) y después de los 17 (las muchachas). Prefieren las pastillas anticonceptivas a los métodos de barrera, tipo preservativo. Los varones justifican su falta de protección en el apasionamiento que les produce la excitación sexual.

En general, demuestran poco conocimiento sobre las ITS, aunque las han escuchado mencionar. Consideran la sífilis una enfermedad ajena y pocos tienen información sobre la gonorrea. Sí conocen el VPH, pero lo confunden con el virus herpes de transmisión sexual. En los casos en que dicen estar más informados (como en el VIH-sida) manejan información superficial y rodeada de mitos. Ante esta enfermedad, por ejemplo, están llenos de pánico y de confusión. La fuente más frecuente de información son los amigos, luego internet, los medios de comunicación tradicionales (especialmente televisión), luego los padres y finalmente la consulta médica. Las organizaciones universitarias nunca son mencionadas, salvo iniciativas esporádicas o muy puntuales.

La mayoría afirma tener relaciones sexuales frecuentemente, pero no tienen pareja fija y consideran importante la protección durante el sexo, especialmente para prevenir embarazos. En todo caso, las dos jóvenes que insistieron en la protección posteriormente confesaron haber sufrido una ITS.

De cualquier manera, incluso los más informados sobre el asunto aparentemente, no cambiaron su conducta sexual. Aceptan que los estudiantes sí necesitan información y la prefieren clara, concreta y sistemática ("pero no todo el tiempo, porque se vuelve aburrida"). Desde luego, afirman que la información debe resultar entretenida, divertida. Si es posible, deberían desarrollarse juegos que informen o aplicaciones e incluso seriados dramáticos para teléfonos móviles. Algunos aseguran que los mensajes deben llevar un sentido de alerta, de advertencia, que los alarme un poco, pero que no los asuste.

Esta última recomendación se repitió en los grupos focales: la información referida a las ITS debe alertar, pero no asustar, porque sería rechazada. En los grupos también se encontró que la fuente más frecuente de información sobre ITS son las conversaciones entre amigos y luego Internet. En las discusiones surgió un elemento interesante: aseguran que si bien se exponen con frecuencia a la televisión y a la radio, esto no significa que los consideren la mejor vía para entender el problema de las ITS. No los descartan, pero los consideran vías de entretenimiento.

Más que saber cómo son las enfermedades, prefieren que se les diga cómo prevenirlas, cómo protegerse y cuáles son las principales vías de transmisión así como las señales para reconocerlas en las parejas sexuales. Y, desde luego, a dónde ir para tratarse en caso de infección. Quieren información práctica, para decirlo con sus propias palabras. 
No creen en las agendas informativas sobre el tema de los medios de comunicación tradicionales pues sienten que la información que les proporcionan es trivial o muy general. Prefieren la información cara a cara o por Internet, siempre y cuando sea interaccional (Facebook aparece como una opción atractiva) y muy visual. Y esperan que siempre esté disponible. Privilegian charlas, foros, compartir experiencias con personas de su edad, pero que tengan información válida. Insisten en que los estudiantes deben ser actores principales en la estructuración de mensajes o en el intercambio de información en las charlas, aunque quieren recibir información también de especialistas.

Sin ánimo de generalizaciones, que ningún sentido tendrían en un trabajo como el que hemos abordado, llama la atención una coincidencia entre estos hallazgos y los de otras investigaciones basadas en métodos cuantitativos. Por ejemplo, dos estudios realizados en Tailandia (Weiss y otros, 1996), insisten en que a los jóvenes les interesa compartir información entre ellos sobre temas de sexualidad, porque se sienten más en confianza. Es también un aspecto sobre el que hacen énfasis los estudios sobre jóvenes realizados por el FNUAP. Estos mismos estudios señalan que los estudiantes también quisieran escuchar a adultos expertos o "gente que sepa del asunto", a decir de dos de nuestros entrevistados.

Eso parece indicar que el medio que los jóvenes privilegian para informarse con profundidad sobre estos temas es la comunicación cara a cara, y ella debe ser el principal mecanismo informativo a la hora de desarrollar campañas o programas de comunicación / información para la prevención de las ITS.

\section{Conclusiones}

De alguna manera, los jóvenes acusan cierta soledad y abandono por parte de los adultos en materia de información sobre su sexualidad. Probablemente esto se deba a los falsos pudores y a elementos culturales que nos acompañan desde hace siglos. Sin embargo, dada la peligrosidad y el riesgo de muerte ante el que nos ponen las ITS que en este momento circulan por el planeta, habría que plantear a padres y maestros una revisión de sus paradigmas y de su práctica en esta materia.

A simple vista, pareciera que la amplia diseminación de las ITS entre los jóvenes podría reducirse si se trabaja en función de llenar necesidades de información / comunicación, puesto que estas son algunas de las carencias que más expresan. Y parte de estos requerimientos podrían satisfacerse con comunicación interpersonal, desde el hogar y en la escuela, y a partir de edades más bien tempranas.

Para quienes trabajan en el diseño de políticas sanitarias y de comunicación para la salud, la presente investigación arroja algunos insumos que pueden resultar de gran utilidad si se piensa en desarrollar intervenciones comunicacionales: por un lado no parece eficiente gastar grandes sumas en costosos avisos en medios de comunicación tradicionales pues aparentemente este sector no los usa para apropiarse de información sobre ITS. 
Los medios de comunicación social convencionales, si bien suministran informaciones y valores sobre sexualidad y formas de vida, no satisfacen las necesidades crecientes de este grupo, que acude a ellos esencialmente para obtener entretenimiento y distracción. Otra cosa es Internet y las redes sociales. A estos medios habría que dedicar más esfuerzos e inversión, especialmente porque tienen uso en la medida en que se convierten en espacios de diálogo.

Queda claro que informar sobre prevención y riesgos de las ITS es muy importante pero no es suficiente. De hecho, aunque de forma superficial, los estudiantes habían oído mencionar estas enfermedades y tenían nociones sobre su riesgo. Pero hace falta algo mucho más trascendente: la comunicación, con todo el impacto interpersonal que ella implica, para que se produzcan los cambios de actitud y de conducta que hacen falta para prevenir las ITS.

Es imprescindible incorporar el sentido del placer, de la vida, de lo lúdico, a los mensajes sobre salud sexual y prevención de las ITS. De esta manera, no sólo se interesará a los jóvenes (que tienen una clara dimensión hedonista), sino también se proporcionará una dimensión más vital y humana a estos temas. La forma tradicional de comunicar sobre ITS, en la que se muestran consecuencias fatales o de alta peligrosidad, no parece eficiente para motivar a jóvenes estudiantes universitarios. Incluso, la posibilidad de desarrollar juegos o seriados y aplicaciones para teléfonos móviles (con información sobre ITS) luce como un desafío tecnológico y comunicativo que podría resultar interesante para los diseñadores de políticas sanitarias y de prevención.

Las universidades deben tomar un papel más activo en la producción de información, ya sea a través de cátedras abiertas, encuentros, charlas o foros de periodicidad frecuente o incorporando el tema en las páginas institucionales. Es sorprendente que las casas de estudio, el espacio en el que los jóvenes invierten más tiempo y donde mantienen parte importante de sus juegos sexuales, no estén incorporando estos temas a los distintos ejes curriculares o extracurriculares.

Se recomienda que, para diseñar ejes o intervenciones comunicativas orientadas a estudiantes universitarios sobre temas relacionados con promoción de la salud sexual y reproductiva, se asuma las nociones de comunicación para la salud, que postula una perspectiva compleja en la cual la comunicación se relacione con diferentes disciplinas, pero también con los llamados "saberes vulgares" o de sentido común, imprescindibles para entender a las audiencias, su lógica de acción, sus necesidades y el sentido que quisieran imprimirle a los cambios (Uranga, Femia y Díaz, 2002).

\section{Fuentes consultadas}

Agüiño, R. (2010). De boca en boca, a ti también te toca: conocer, informar, prevenir el VPH. Campaña de información sobre el virus de papiloma humano en la UCAB [Trabajo especial de grado]. Caracas: Universidad Católica Andrés Bello, Escuela de Comunicación Social, Mimeo.

\section{Barrios, L.}

_(1999, junio 7-11). "Psicosociología de las ETS y el Sida". Ponencia presentada en el 
Congreso Latinoamericano de Ciencias Sociales y Medicina”. Margarita, Venezuela. _(1993): Familia y televisión. Caracas: Monte Ávila Latinoamericana.

Canales, M. y Peinado, A. (1999). “Grupos de discusión”. En Delgado, J. y Gutiérrez, J. (coords.) Métodos y técnicas cualitativas de investigación en Ciencias Sociales. Madrid: Síntesis Psicología.

Carvajal, A.; Oletta, J. y Peña, S. (2012). "Sobre el Día Internacional de la Mujer”. Red de Sociedades Cientificas y Médicas de Venezuela. Extraída el 26/VIII/2013 desde http:// www.rscmv.org.ve/

Coe, G. (1998). Comunicación social y salud de los trabajadores. Caracas: Mimeo.

Correnti, M. y otros (2002). "La Infección por el VPH: un problema de salud pública en Venezuela". Revista Vitae. Academia Biomédica Digital. Facultad de Medicina de la Universidad Central de Venezuela, núm. 13. Extraída el 3/IV/2013 desde http://vitae.ucv. ve $/ ?$ module $=$ articulo\&rv $=85 \& n=3575$

Freitez, A. (2001). "Encuesta Nacional de Población y Familia 1998. Fondo de Población de Naciones Unidas”. Extraída el 20/II/2012 desde http://venezuela.unfpa.org/doumentos/ Informe\%20enpofam.pdf

González Gaitano, N. (2000). "El Síndrome de Scherezade y otros síndromes deseducativos de la televisión”. Revista Arvo. Extraída el 28/IX/2012 desde http://arvo.net/educar-enfamilia/el-sindrome-de-scherezade/gmx-niv135-con10245.htm

Guzmán, C. y otros (1998). El consumo cultural del venezolano. Caracas: Fundación Centro Gumilla, Consejo Nacional de la Cultura.

Fondo de Población de las Naciones Unidas (1998). Estado de la población mundial 1998. Las nuevas generaciones. Nueva York: FNUAP.

Ministerio del Poder Popular para la Salud (2011). Anuario de Morbilidad. Caracas: Ediciones del MPPS.

Organización de las Naciones Unidas para la lucha contra el VIH-Sida (2012). "Informe de ONUSIDA para el Día Mundial del Sida". Extraída el 17/III/2013 desde http://www. unaids.org/en/media/unaids/contentassets/documents/unaidspublication/2012/JC2434 WorldAIDSday_results_es.pdf Recuperado el 17 de marzo de 2013

Organización de las Naciones Unidas para la lucha contra el VIH-Sida. Capítulo Venezuela (2012). "Informe nacional de avances en la implementación de la declaración de compromisos sobre VIH/Sida (2001) y la declaración política sobre VIH/Sida (2006 y 2011)". Extraída el 6/VI/2013 desde http://www.onusida-latina.org/images/2012/mayo/ ce_VE_Narrative_Report[1].pdf 
Parra, L. (2004). "Dinámicas de percepciones sobre prácticas de comunicación y salud". Estudios venezolanos de Comunicación, núm. 126.

Red de Sociedades Científicas Médicas Venezolanas.

_(2013). "Balance de salud del año 2012 en Venezuela. Alerta Epidemiológica No 246". Extraída el 4/II/2013 desde http://www.rscmv.org.ve/pdf/ALERTA_246.pdf _(2012). "Noticias Epidemiológicas N³4"- Caracas: RSCMV.

Rodríguez, G.; Gil, F. y García, J. (1996). Metodología de la investigación cualitativa. Málaga: Aljibe.

Santoro, E. (1998). "La televisión venezolana y la formación de estereotipos en el niño. 30 años después”. Extramuros, núm. 8, pp. 16-34.

Sáez, I. y Sileo, E. (1992). Medicina del adolescente. Aproximación al adolescente sano. Caracas: Ministerio de Sanidad-UNICEF-OPS-OMS.

Uranga, W.; Femia, G. y Díaz, H. (2002, octubre 18-30). “Acerca de la práctica social de los comunicadores. Consideraciones teóricas, metodológicas y políticas. Una mirada sobre comunicación y salud". Ponencia presentada en el II Congreso Nacional de Comunicación y Salud. La Paz, Bolivia. Extraída el 13/X/2012 desde www.cpcbol.org/Archivo\%20-PDF/

Washin\%20uranga.pdf

Weiss, E. y otros (1996). Vulnerabilidad y oportunidad: Los adolescentes y el VIH/Sida en el mundo en desarrollo. Washington: International Center for Research on Women. 